\title{
Role of Ankle Foot Orthoses in the Outcome of Clinical Tests of Balance
}

\author{
BY \\ NILOVANA AJIT PANWALKAR \\ B.P.Th., KCPT MUHS, 2010.
}

\section{THESIS}

Submitted as a partial fulfillment of the requirements for the degree of Master of Science in

Rehabilitation Sciences in the Graduate College of the University of Illinois at Chicago, 2012 Chicago, Illinois

Defense Committee:

Dr. Alexander Aruin, Chair and Advisor

Dr. Christina Hui-Chan.

Dr. Tanvi Bhatt. 
This thesis is dedicated to my parents (Mr. Ajit Panvalkar and Mrs. Archana Panvalkar), brother (Niul Panvalkar) without whom it would never have been accomplished. 


\section{ACKNOWLEDGEMENTS}

I would like to thank my thesis advisor Dr. Alexander Aruin for his tremendous support and assistance. I would also like to thank my Thesis Defense Committee members Dr. Alexander Aruin, Dr. Christina Hui Chan and Dr. Tanvi Bhatt for their valuable guidance. They provided assistance in different areas that helped me accomplish my research goals and enjoy myself in the process.

A number of individuals in the Knecht Movement Science Laboratory were very helpful to me during data collection, and I would like to thank them as well- Sambit, Neeta, Vennila, Ketaki and Bing.

Finally, I would like to thank my parents, family and friends for their support during the last 2 years.

-N.A.P 


\section{TABLE OF CONTENTS}

\section{CHAPTER I}

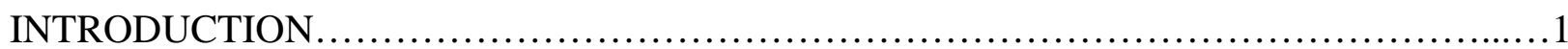

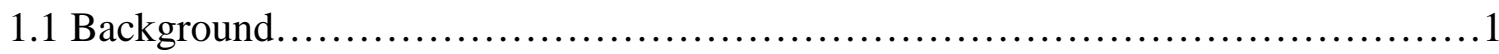

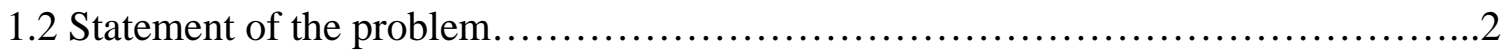

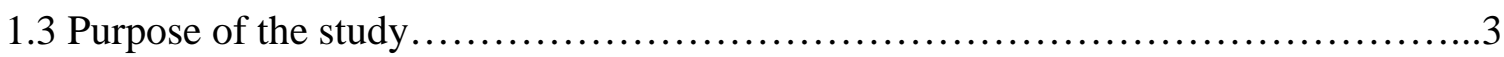

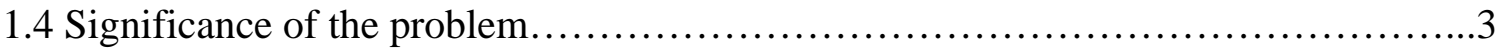

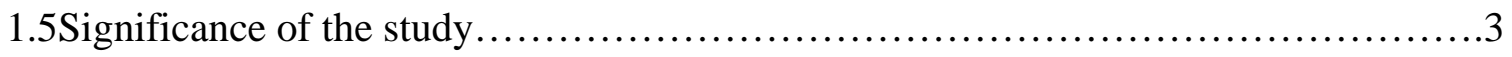

\section{CHAPTER II}

LITERATURE REVIEW .................................................................

2.1Balance Control...................................................................

2.2 modified Clinical Test of Sensory Interaction on Balance ..........................

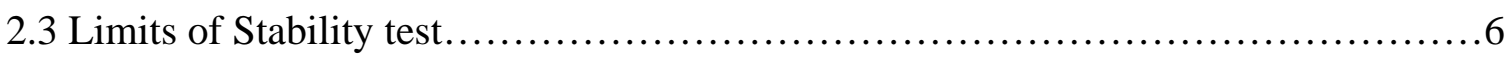

2.4 Functional Reach test............................................................

2.5 Lack of data on prescription of orthotics while

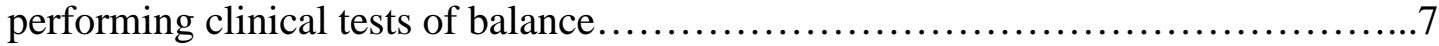

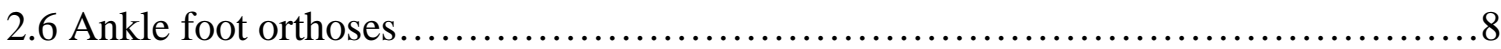

\section{CHAPTER III}

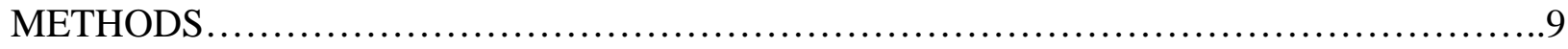

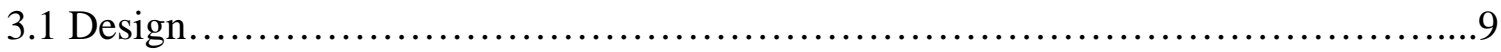

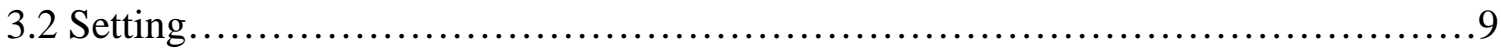

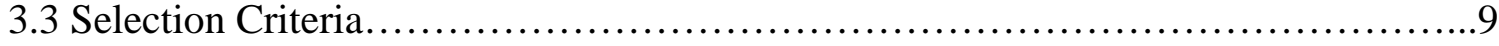

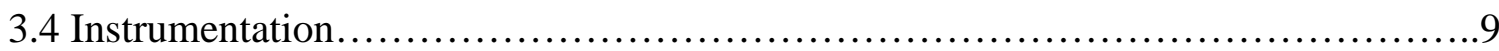

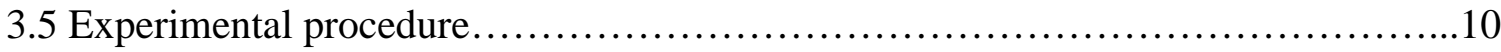

3.5.1 modified Clinical Test of Sensory Interaction on Balance..................10

3.5.2 Limits of stability test.....................................................

3.5.3 Functional Reach test............................................ 12

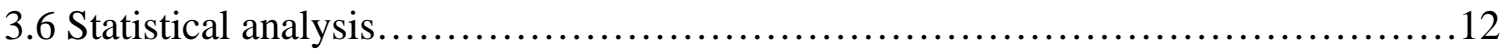




\section{TABLE OF CONTENTS (continued)}

\section{CHAPTER IV}

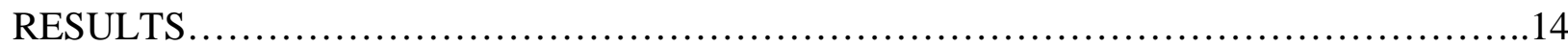

4.1 modified Clinical Test of Sensory Interaction on Balance..........................14

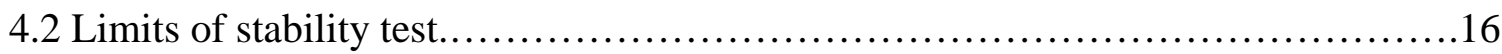

4.3 Functional Reach test......................................................... 18

\section{CHAPTER V}

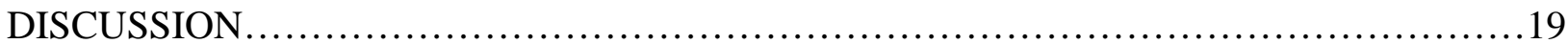

5.1 Role of Ankle Foot Orthoses in modified Clinical Test of Sensory Interaction of Balance.............................19

5.2 Role of Ankle Foot Orthoses in Limits of Stability test.............................20

5.3 Role of Ankle Foot Orthoses in Functional Reach test.............................22

\section{CHAPTER VI}

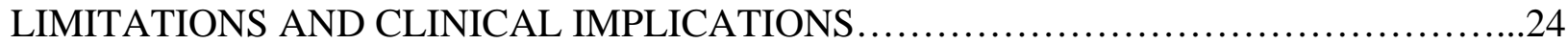

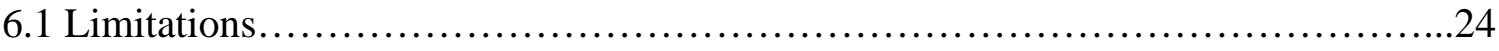

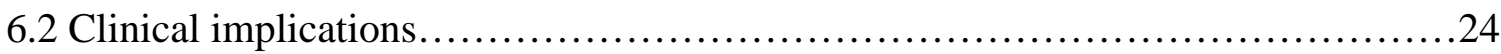

\section{CHAPTER VII}

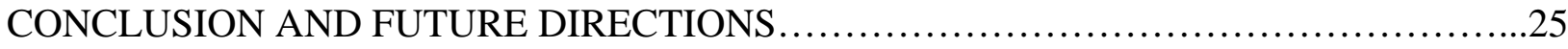

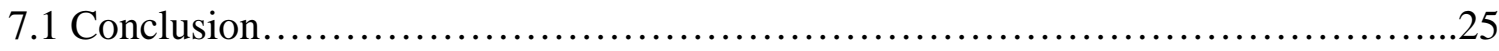

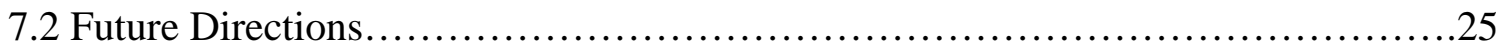

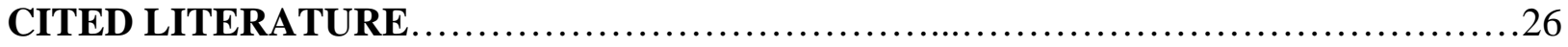

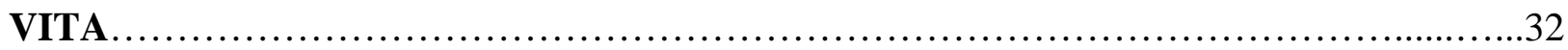




\section{LIST OF FIGURES}

FIGURE

$\underline{\text { PAGE }}$

1. Illustration of NeuroCom Balance Master...............................................4

2. Demonstration of modified Clinical Test of Sensory Interaction on Balance....................................................

3. Demonstration of Limits of Stability test....................................... 6

4. Demonstration of Functional Reach test..........................................

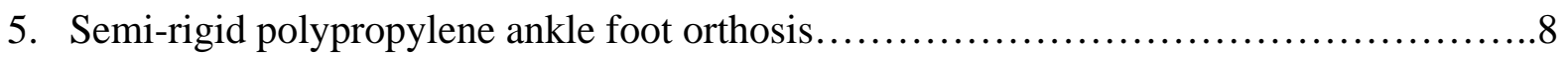

6. Graph showing COG sway velocities obtained from mCTSIB.......................14

7. Graph showing results of Reaction time, Movement velocity, End point excursion, Maximum excursion and Directional Control (LOS

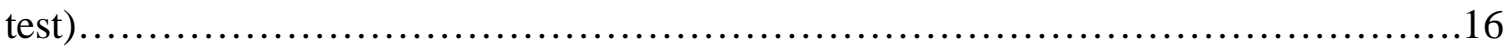

8. Graph showing forward reach distance obtained from

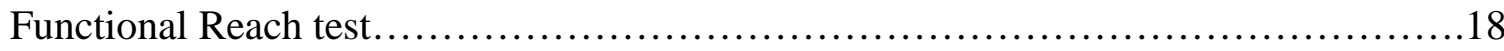




\section{LIST OF ABBREVIATIONS}

$\begin{array}{ll}\text { AFOs } & \text { Ankle Foot Orthoses } \\ \text { mCTSIB } & \text { modified Clinical Test of Sensory Interaction on Balance } \\ \text { COG } & \text { Limits of Stability } \\ \text { RT } & \text { Center of Gravity } \\ \text { MVT VEL } & \text { Reaction Time } \\ \text { DC } & \text { Movement Velocity } \\ \text { END PT EX } & \text { Directional Control } \\ \text { MAX EX } & \text { End Point Excursion } \\ \text { ANOVA } & \text { Maximum Excursion }\end{array}$




\section{SUMMARY}

The main purpose of this thesis was to explore the role of ankle foot orthoses (AFOs) on the outcomes of clinical tests of balance. First chapter (Chapter One) introduces the thesis by first describing the background of ankle foot orthoses and their uses in patient populations. It also describes the biomechanical effect of wearing AFOs. Later on, is describes how the use of AFOs can affect the outcome of clinical tests of balance assessments. It describes the statement of problem, the purpose of conducting the study, the significance of the problem and the significance of conducting this study.

Chapter Two describes the literature examining the importance of balance control and various clinical tests used for balance assessments. It describes the three tests used for the studymodified Clinical Test of Sensory Interaction on Balance (mCTSIB), Limits of Stability (LOS) test and Functional Reach test illustrated with figures. mCTSIB test assesses the patient's functional balance control in conditions where visual and proprioceptive information is accurate and where it is compromised. The testing protocol includes four sensory conditions: standing on firm surface of a force platform with eyes open or closed (vision is compromised) and standing with eyes open or closed on foam positioned on top of the force platform (proprioception is compromised). The computer software calculates the mean COG sway velocity. The LOS test assesses the maximum distance a person can intentionally displace their COG from start position to eight targets following a moving cursor on the display monitor. The outcomes calculated were Reaction time, Movement velocity, End point excursion, Maximum excursion and Directional control. The Functional Reach test measures the maximum distance reached in a forward direction. Later on in this chapter lack of data available on prescription of orthotics while 
performing clinical tests of balance is described. The association between ankle foot orthoses and clinical tests of balance is then described.

Chapter Three describes the design of the study, the setting in which the study was conducted and the selection criteria which includes details of the subjects participating in the study and the exclusion criteria. Ten healthy subjects with an average age of $24.9 \pm 2.47$ years participated in the study. Later on it describes the instrumentation used for this study and the step-by-step experimental procedure followed for the three clinical tests- modified Clinical Test of Sensory Interaction on Balance, Limits of Stability test and Functional Reach test performed in the study. This chapter also describes the statistical analysis used in the study.

Chapter Four describes all the results obtained from the three clinical tests of balance. In mCTSIB test the mean COG sway velocity was the highest when the test was performed with AFOs in eyes closed condition on foam surface. The increase in COG sway velocity was statistically significant $(\mathrm{p}=0.042)$.

In LOS test the decrease in mean End point excursion with AFOs was found to be statistically significant $(\mathrm{p}=0.018$ ). The decrease in mean Maximum excursion with AFOs was also found to be statistically significant $(\mathrm{p}=0.021$ ). In Functional Reach test the decrease in reach distance on wearing AFOs was found to be statistically significant $(\mathrm{p}=0.003)$.

It states all the values of each parameter measured of all three clinical tests used and also highlights the statistically significant values. This chapter contains graphs for all three tests. Chapter Five discusses the role played by ankle foot orthoses in the outcomes of the clinical tests of balance performed in the study- modified Clinical Test of Sensory Interaction on Balance, Limits of Stability test and Functional Reach test. Chapter Six describes limitations of the study and its clinical implications. Chapter Seven describes the conclusions drawn out of the study. 
It also describes how this present study can serve as a foundation for future research work describing some possibilities and directions for future research work involving use of electromyography and different kinds of orthoses. 


\section{CHAPTER I}

\section{INTRODUCTION}

\subsection{Background}

Ankle foot orthoses (AFOs) that hold the foot and ankle in an aligned position thus preventing foot-drop, are frequently prescribed for patients with paretic ankle dorsiflexor muscles in order to improve walking ability and to prevent stumbling (Jaivin et al. 1992; Mulroy et al. 2010). Multiple studies reported the efficacy of AFOs in improving gait in individuals with stroke (Chen et al. 1999; Pohl and Mehrholz 2006; Chen et al. 2008; Cakar et al. 2010; Dogan et al. 2011; Silver-Thorn et al. 2011), cerebral palsy (Abel et al. 1998; Butler et al. 2007; Hayek et al. 2007) and multiple sclerosis (Sheffler et al. 2008).

While the majority of patients are prescribed with unilateral AFOs (Rubin and Cohen 1988; Fatone et al. 2009; Tyson and Kent 2009), there are a number of adults (e.g. with a spinal cord or peripheral nerve diseases) and pediatric patients (e.g. with spastic diplegic cerebral palsy) who are users of bilateral AFOs (Brodke et al. 1989; Radtka et al. 2005; Rha et al. 2010). Orthotic professionals estimate that there are about $10 \%$ of the total adult and about $50 \%$ of pediatric AFO users who are recipients of bilateral AFOs (Hasso 2012).

By design, AFOs limit the motion of the ankle joint in one or more planes and, therefore are considered as a kind of exoskeleton, the mechanical properties and alignment of which are closely related to functional performance (Gao et al. 2011). Moreover, since the motion in the ankle joint is limited by an AFO, the proprioceptive afferent input from the muscles, tendons, and other tissues of the ankle joint is restricted (Richie 2001); this increases the individual's need to rely on visual and vestibular cues in order to maintain balance. Furthermore, while AFOs help 
with the management of various pathological conditions, the role of AFOs in relation to balance control is far from a complete understanding (Ramstrand and Ramstrand 2010). This is partially due to a lack of data on the effect of AFOs on the outcome of commonly used clinical balance tests.

There are more than two dozen tests used to asses balance in patients (Yelnik and Bonan 2008; Tyson and Connell 2009). While some of the critical measures clearly restrict the use of assistive devices (Genthon et al. 2008), this requirement is not specified in the description of others (Lee et al. 1988). Moreover, while the majority of clinical tests for balance require patients to be barefoot while testing, there are many reasons why this is not evident when administering these tests routinely. As a result, the outcomes of these clinical tests of balance might not always reflect the true balance ability of a patient.

The aim of the study was to investigate the effect of AFOs on the outcome of balance assessment. To minimize the interference by co-morbidities which might be apparent in the patient population, we studied healthy subjects. Simulating conditions of AFOs used by a patient population allows evaluation of the effect of AFOs on clinical assessment of balance with no interference by the co-morbidities. We hypothesized that the use of AFOs would affect the outcome of balance assessments.

\subsection{Statement of the problem}

Outcomes of clinical tests of balance are extremely important in order to obtain an objective measure of ability of a patient to maintain balance. Patient populations are often tested with or without orthotic and prosthetic devices. As a result there is a possibility of introduction of variability in balance scores which might affect outcomes of clinical tests of balance. Hence there is a need to study the effect of ankle foot orthosis on the outcome of clinical tests of 
balance. It is equally important to minimize interference by co-morbidities which might be apparent in patient population. So a healthy population was chosen to study the effect of ankle foot orthosis which could be then implied in the measurement of balance in patient population.

\subsection{Purpose of study}

The purpose of this study was to investigate the effect of ankle foot orthoses on balance assessment using commonly used clinical tests of balance.

\subsection{Significance of problem}

AFOs are commonly used to treat a variety of pathologies affecting joint stability and neuromuscular insufficiency. However, because of inherent effects on the ankle joint, AFOs may have positive or negative impacts on balance. As a result, when individuals using AFOs undergo balance assessment, the outcome of the tests frequently reflects the effect of both, the impairment and AFOs. To evaluate the effect of AFOs per se and to minimize the effect of the presence of any kind of co-morbidity healthy individuals need to be tested.

\subsection{Significance of study}

Knowledge of the AFO-related sources of measurement error can provide meaningful information for clinicians who perform tests of balance or evaluate patient progress during the course of a balance intervention program. The study emphasizes a need for reviewing the descriptions of clinical tests of balance with the focus on clarifying the use of AFOs during the tests so the consistency and repeatability of the assessments is maintained. 


\section{CHAPTER II}

\section{LITERATURE REVIEW}

\subsection{Balance control}

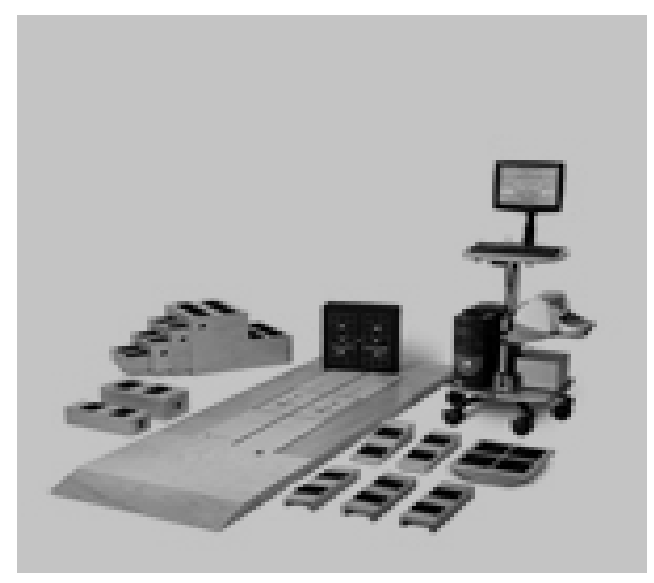

Fig 1. Illustration of NeuroCom Balance Master

Balance is defined as the ability to maintain a position within the limits of stability or base of support (Tyson and Connell 2009). Goals of balance are to maintain postural alignment, to facilitate voluntary movement and to recover equilibrium incase external forces are applied to the body (Cakar et al. 2010). Healthy humans are able to maintain balance using properly scaled activation of muscles however balance is compromised in individuals with musculoskeletal and neuromuscular pathologies. Accurate evaluation of balance is important for prescribing appropriate mobility aids, determining the most effective treatment interventions, and identifying safe and unsafe activities related to impairment or pathology. Different batteries of clinical tests are used to measure balance which includes Barthel Index, Fugl-Meyer Test, Timed up \& Go Test, Tinetti balance scale and the Functional Reach test (Tyson and Connell 2009).

Computerized measurement and feedback systems devised to assess and train static and dynamic balance performance are also available. These systems are comprised of hardware and software to provide quantitative information and feedback pertaining to stability and weight transference. 
Menu-driven test suites have been developed to isolate and challenge the sensory and motor components of balance at various levels of difficulty. mCTSIB and LOS test from the NeuroCom Balance Master (NeuroCom, USA) and the Functional Reach test were chosen to test the healthy subjects as they are commonly used and inexpensive tools of balance measurement.

\section{2 modified Clinical Test of Sensory Interaction on Balance}

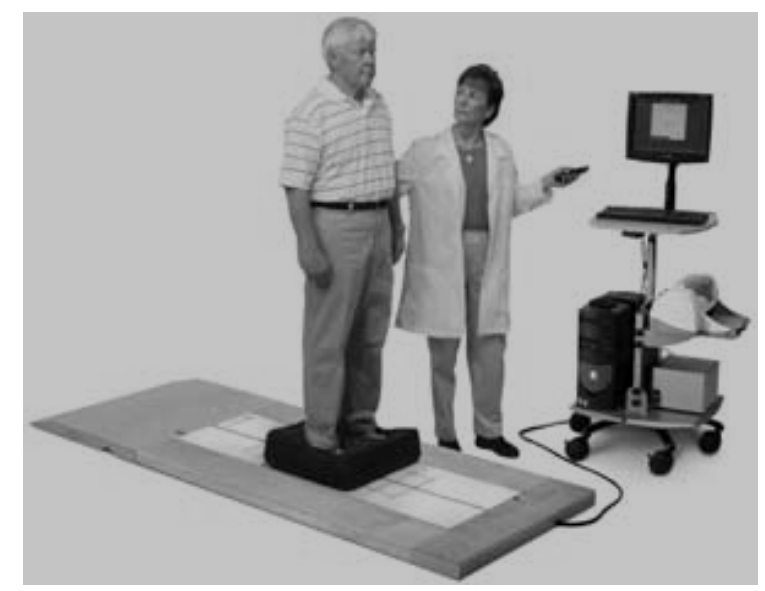

Fig 2. Demonstration of modified Clinical Test of Sensory Interaction on Balance

In a study, modified Clinical Test of Sensory Interaction on Balance was examined in three asymptomatic groups divided into younger, middle-aged and older age group and a group of subjects diagnosed with vestibular disorders. The results of this study showed that the subjects with vestibular disorders showed significantly worse performance when compared with age matched healthy subjects. Moreover, this test was found to be a useful screening tool for examining static standing balance (Cohen et al. 1993). 


\subsection{Limits of Stability test}

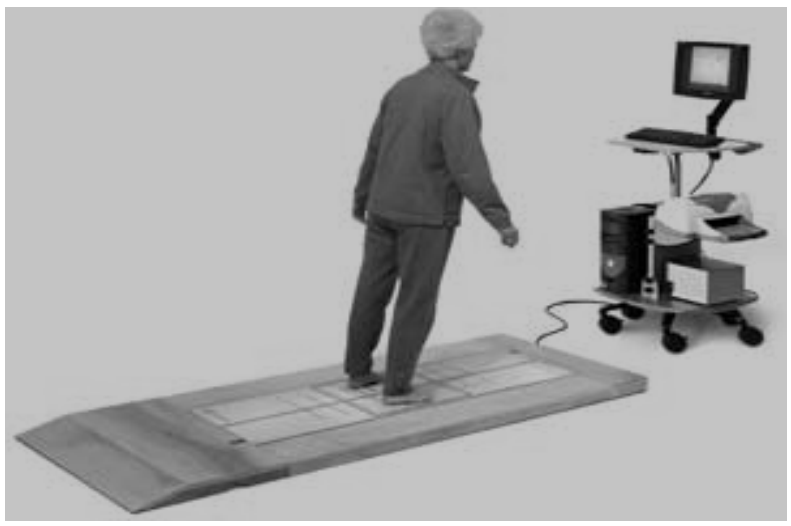

Fig 3. Demonstration of Limits of Stability test

The LOS test is commonly used in clinical assessment of balance. It measures the ability of a person to control intentional movements of the center of gravity (COG) when leaning or performing weight shifting activities which is critical to the successful performance of various functional tasks associated with activities of daily living (ADLs). The LOS test is considered a reliable assessment of dynamic balance when administered to healthy young and older adults with no recent history of falls (Clark et al. 1997; Newstead et al. 2005). 


\subsection{Functional Reach test}

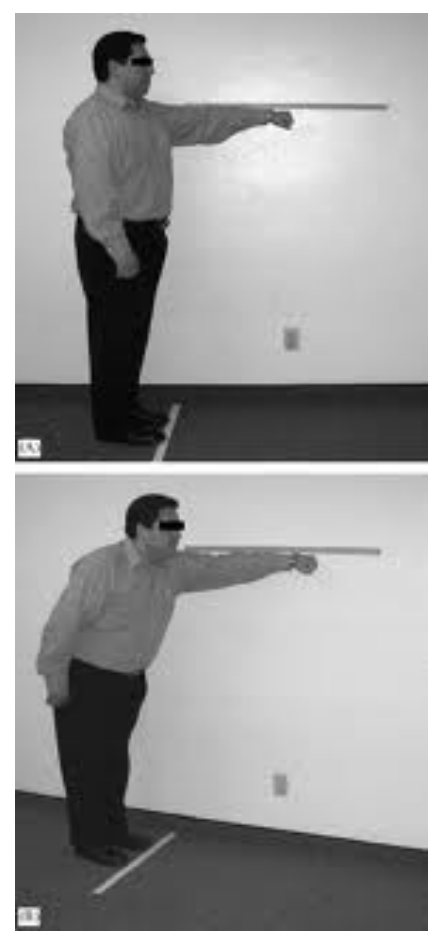

Fig 4. Demonstration of Functional Reach test

The Functional Reach test measures the maximum distance reached in a forward direction. It was shown that the Functional Reach test has a high predictive validity, test-retest reliability and interobserver reliability for younger and older adults (Duncan et al. 1990; Duncan et al. 1992; Hageman et al. 1995).

\subsection{Lack of data on prescription of orthotics while performing clinical tests of balance}

There have been studies in the past where the use of assistive devices has been clearly restricted while there are some other studies where this requirement is not specified. For example in one study, the percentage of body weight on each leg was compared between two groups- one healthy and the other consisting of hemiparetic subjects using a dual force platform. In this study 
the use of assistive devices was restricted where all subjects were tested without any technical or human aid (Genthon et al. 2008). Another study focused on quantitative and clinical measures of static standing balance in subjects with hemiparesis and healthy controls. In this study there was no restriction on use of assistive device and the clinical tests of balance were conducted in patients with or without their orthosis. (Lee et al.1988).

\subsection{Ankle foot orthoses}

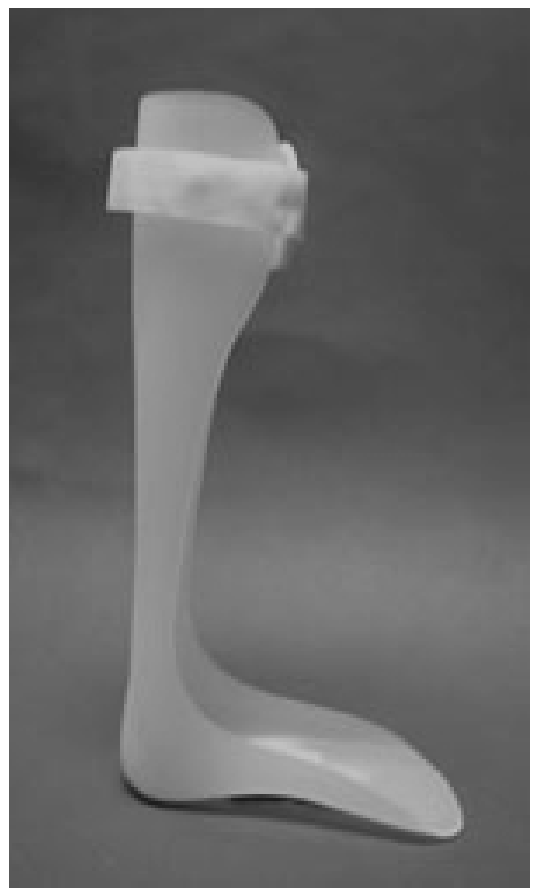

Fig 5. Semi-rigid polypropylene ankle foot orthosis

Ankle Foot Orthoses are commonly used to treat a variety of pathologies affecting joint stability and neuromuscular insufficiency. AFOs hold the foot and ankle in an aligned position and prevent foot drop. Multiple studies reported the efficacy of AFOs in improving gait in different patient populations. However there is lack of data on the effect of AFOs on the outcome of commonly used clinical balance tests. 


\section{CHAPTER III}

\section{METHODS}

\subsection{Design}

The study was conducted in a single group of healthy subjects tested with and without ankle foot orthoses.

\subsection{Setting}

All experiments were performed at the Harry G Knecht Laboratory in the Department of Physical Therapy at the University of Illinois at Chicago.

\subsection{Selection criteria}

Ten healthy individuals of average age $24.9 \pm 2.47$ years with normal vision, or corrected to normal vision, participated in the study. There were five males and five females with a height of $168.4 \pm 8.3 \mathrm{~cm}$ and weight of $64.02 \pm 13.5 \mathrm{~kg}$. Those on antidepressants, anxiolytics, sedatives and hypnotics were excluded. The study was approved by the University of Illinois at Chicago Institutional Review Board and informed consent was obtained from subjects prior to study participation.

\subsection{Instrumentation}

A pair of prefabricated, appropriate sized, semi-rigid polypropylene ankle foot orthoses was used. During all of the tests the subjects were provided with a pair of standardized sandals to minimize the effect of footwear on the study outcome. The sandals had adjustable Velcro straps which allowed for a proper fitting. To perform the modified Clinical Test of Sensory Interaction on Balance (MCTSIB) and the Limits of Stability (LOS) test, the Balance Master® (NeuroCom, 
USA) was used. It includes a dual force platform connected to a computer. To measure the forward reach distance in Functional Reach Test a tape measure was affixed to the wall.

\subsection{Experimental procedure}

Clinical assessments of balance were performed with and without AFOs. A pair of prefabricated, appropriate sized, semi-rigid polypropylene ankle foot orthoses was used. These AFOs were sturdy enough to limit ankle motion to a few degrees during the clinical tests of balance. During all of the tests the subjects were provided with a pair of standardized sandals to minimize the effect of footwear on the study outcome. The sandals had adjustable Velcro straps which allowed for a proper fitting. Prior to the test, the subjects were able to familiarize themselves with the use of AFOs. No participant complained of discomfort during testing. The order of balance tests and the order of experiments with wearing AFOs and no AFOs was randomized.

The Balance Master® (NeuroCom, USA) that includes a dual force platform connected to a computer was used to perform the modified Clinical Test of Sensory Interaction on Balance (mCTSIB) (Cohen et al. 1993) and the Limits of Stability (LOS) test (Newstead et al. 2005).

\subsection{1 modified Clinical Test of Sensory Interaction on Balance}

The mCTSIB test assesses the patient's functional balance control in conditions where visual and proprioceptive information is accurate and where it is compromised. The testing protocol included four sensory conditions: standing on a firm surface of a force platform with eyes open and closed (vision was compromised) and standing with eyes open or closed on foam positioned on the top of the force platform (proprioceptive information and vision were compromised) (Brodke et al. 1989; NeuroCom 2010). The subjects were positioned on the platform or on the foam using a standard NeuroCom protocol: the lateral borders of their feet were aligned with the 
appropriate height line marked on the force platforms and the medial malleoli were aligned with the transverse force platform line (NeuroCom 2010). The computer software calculated the subject's mean Center of Gravity (COG) sway velocity for the four testing conditions (NeuroCom 2010). The test-retest reliability for the mCTSIB was found to be high (Hageman et al. 1995).

\subsubsection{Limits of Stability test}

The LOS test assesses the maximum distance a person can intentionally displace their center of gravity (COG) from start position to eight targets following a moving cursor on the display monitor (representing the subject's COG) without losing balance, stepping or reaching for assistance (NeuroCom 2010).

During the test, the subjects stood on the force platform with the feet positioned according to the manufacturer's instructions (NeuroCom 2010). They were required to shift their body in the direction of one of the highlighted targets (forward, right forward, right, right backward, backward, left backward, left, left forward) shown on the screen. The subjects were instructed to follow the cursor to each target as it was highlighted using movements about the ankle joints and remain at that target for 3 seconds before returning to the central target (neutral). The maximum allowable movement time to reach a target was 8 seconds. The test provides several outcomes. Among them are: Reaction Time (RT) that is the time in seconds between the command to move and the patient's first movement, Movement Velocity (MVT VEL) that is the average speed of the subject's COG movement in degrees per second, and Directional Control (DC) that is a comparison of the amount of movement in the intended direction (towards the target) to the amount of extraneous movement (away from the target) (NeuroCom 2010) (NeuroCom 2002). In addition, the test allows assessing the subjects' endpoint excursion and maximum excursion. 
Endpoint excursion (END PT EX) is the point at which the initial movement toward the target ceases. Maximum excursion (MAX EX) is defined as the maximum distance up to which the subject is able to shift his/her COG towards the highlighted target: it was calculated as the distance of the first movement toward the designated target, expressed as a percentage of maximum LOS distance (NeuroCom 2010).

\subsubsection{Functional Reach test}

The Functional Reach test measures the maximum distance reached in a forward direction (Duncan et al. 1990). It was shown that the Reach test has a high predictive validity, test-retest reliability and interobserver reliability for younger and older adults (Duncan et al. 1990; Duncan et al. 1992; Hageman et al. 1995). A tape measure was affixed to the wall to measure the reach distance. The position of the feet was controlled during all the parts of the test. The subjects were told to stand erect maintaining the shoulders at the same level and raise one of their shoulders and arms, whichever was comfortable, to $90^{\circ}$. They were instructed to use the hand with which performance of the Functional Reach test was comfortable. The instruction given was to reach as far as they could without losing balance or taking a step in a plane parallel to the tape measure (Duncan et al. 1992). Three trials were recorded and before the recording, each subject was given a practice trial. If the subject took a step in any of the three trials, that trial was discarded. The reach distance was calculated as the difference between the final and the initial position that the subject reached (Duncan et al. 1992). The reach distance was measured in centimeters.

\subsection{Statistical Analysis}

Repeated measures ANOVAs were performed separately to obtain an outcome for each parameter of the MCTSIB test, LOS test and Reach test. In all of the tests, the independent measures were AFOs and no AFOs. The dependent measures for mCTSIB were COG sway 
velocity. The dependent variables for LOS were reaction time (RT), movement velocity (MVT VEL), end point excursion (END PT EX), maximum excursion (MAX EX) and directional control (DC). For Reach test, the dependent variable was the reach distance in forward direction. The level of significance was set at $\mathrm{p}<0.05$. 


\section{CHAPTER IV}

RESULTS

\section{1 modified Clinical Test of Sensory Interaction on Balance}

\section{MCTSIB TEST}
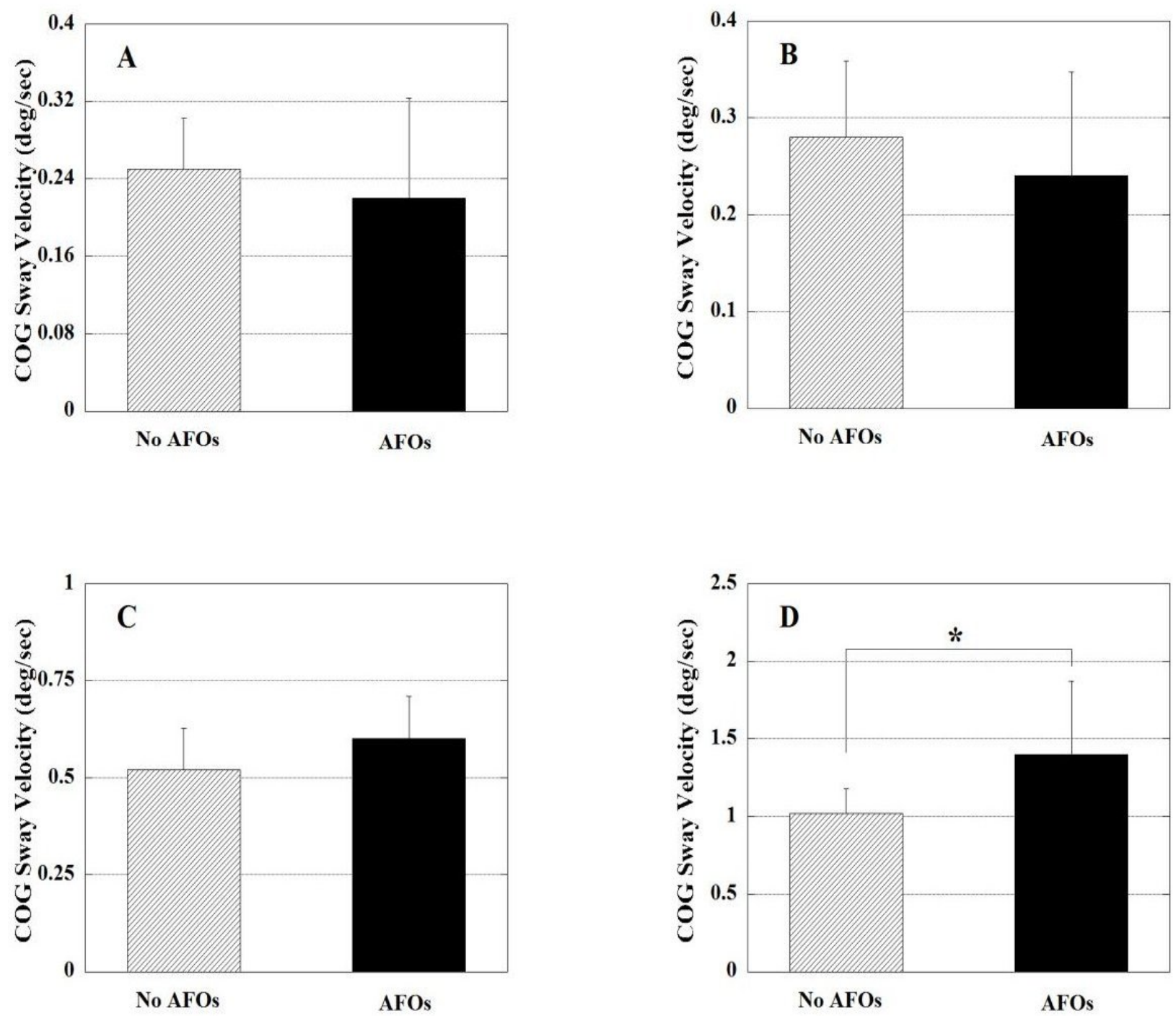

Figure 6. Mean COG sway velocities obtained without AFOs and when AFOs were provided to the subjects (mCTSIB Test). (A) Firm surface, eyes open, (B) Firm surface, eyes closed, (C) 
Foam, eyes open, (D) Foam, eyes closed. Mean and SD are shown.*Statistical significance (p < $0.05)$.

The outcome of the mCTSIB test is shown in Figure 1. The mean COG sway velocity in the eyes open condition on a firm surface without AFOs was $0.25 \pm 0.05 \mathrm{deg} / \mathrm{s}$ and when the AFOs were provided it decreased to $0.22 \pm 0.1 \mathrm{deg} / \mathrm{s}$. When the same task was performed during the eyes closed condition on a firm surface without AFOs the mean COG sway velocity was $0.28 \pm 0.07 \mathrm{deg} / \mathrm{s}$ and when the AFOs were provided it decreased to $0.24 \pm 0.1 \mathrm{deg} / \mathrm{s}(\mathrm{p}>0.05)$. The mean COG sway velocity during the eyes open condition on a foam surface without AFOs was $0.52 \pm 0.11 \mathrm{deg} / \mathrm{s}$ and when AFOs were provided, it increased to $0.6 \pm 0.10 \mathrm{deg} / \mathrm{s}$ $(\mathrm{p}>0.05)$. When the same task was performed during the eyes closed condition on a foam surface without AFOs the mean COG sway velocity was $1.02 \pm 0.16 \mathrm{deg} / \mathrm{s}$ and when AFOs were provided it increased to $1.4 \pm 0.47 \mathrm{deg} / \mathrm{s}$. The increase of COG sway velocity was statistically significant $\left(\mathrm{F}_{(1,9)}=5.61, \mathrm{p}=0.042\right)($ Figure 1$)$. 


\subsection{Limits of Stability}

\section{LOS TEST}
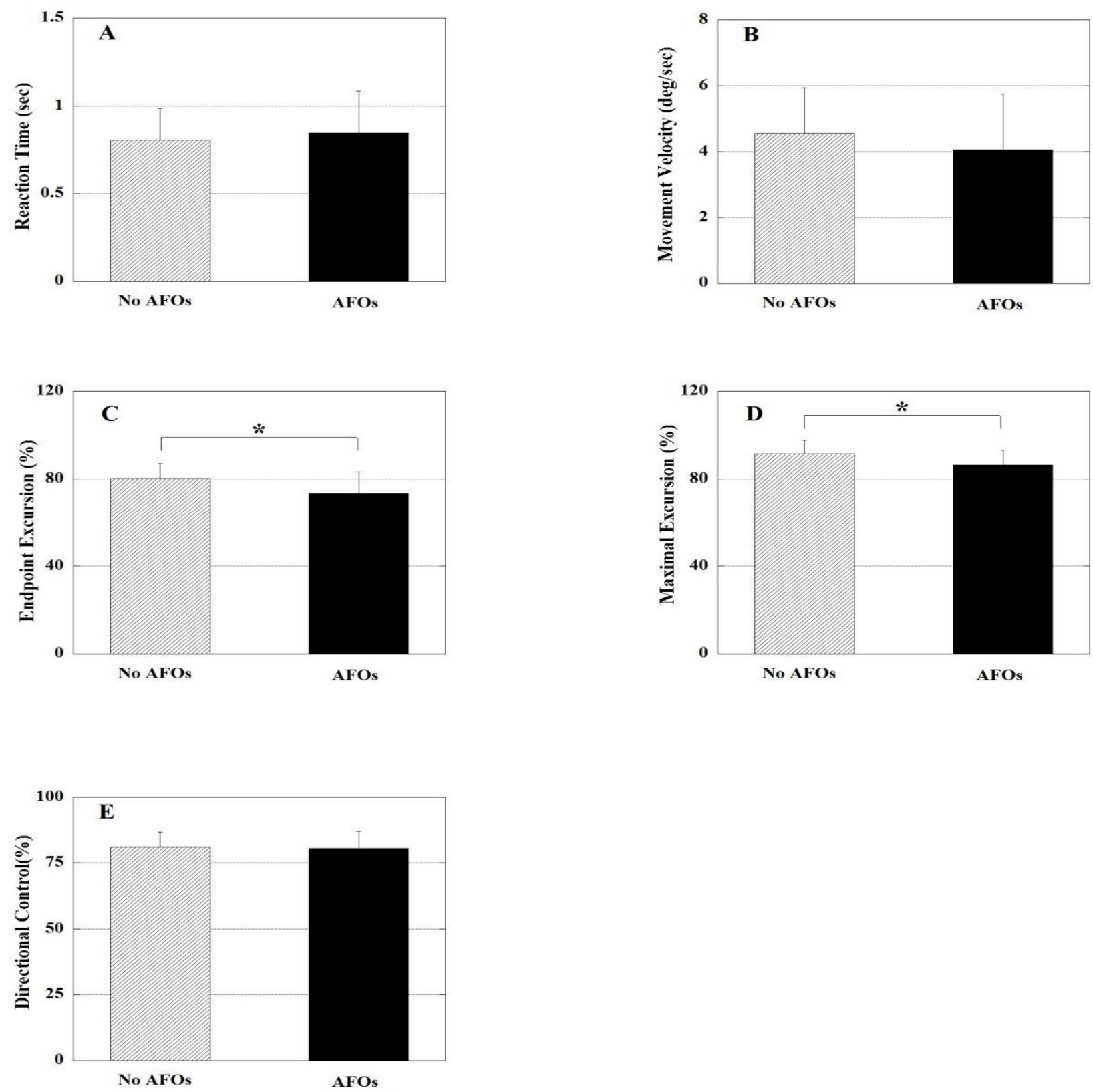

Figure 7. The outcomes of the LOS Test without AFOs and when the subjects were provided with AFOs are shown. (A) Reaction time, (B) Movement velocity, (C) Endpoint excursion, (D) Maximal excursion, and (E) Directional control. Data are calculated across targets. 
*Significance $(\mathrm{p}<0.05)$.

The results of the LOS test are shown in Figure 2. The mean RT without AFOs was $0.8 \pm 0.18 \mathrm{sec}$ and when AFOs were provided it increased to $0.84 \pm 0.23 \mathrm{sec}(\mathrm{p}>0.05)$. The mean MVT VEL without AFOs was $4.55 \pm 1.43 \mathrm{deg} / \mathrm{s}$ and when the subjects were provided with AFOs it decreased to $4.05 \pm 1.74 \mathrm{deg} / \mathrm{s}$ ( $\mathrm{p}>0.05$ ). The mean END PT EX without AFOs was $80.1 \pm 8.9 \%$ and when the subjects were provided with AFOs it decreased to $73.4 \pm 9.6 \%$. The decrease was found to be statistically significant $\left(\mathrm{F}_{(1,9)}=8.34, \mathrm{p}=0.018\right)$. Finally, the mean MAX EX without AFOs was $91.4 \pm 6 \%$ and when the subjects were provided with AFOs it decreased to $86.2 \pm 6.8 \%$; this outcome was statistically significant.

$\left(F_{(1,9)}=7.81, p=0.021\right)$. Figure 2 shows the mean end point excursion (END PT EX) and maximum excursion (calculated across targets) without AFOs and when the subjects were provided with AFOs.

The mean directional control (DC) without AFOs was $80.1 \pm 5.6 \%$ and when the subjects were provided with AFOs it increased slightly to $80.5 \pm 6.6 \%(\mathrm{p}>0.05)$ 


\subsection{Functional Reach Test}

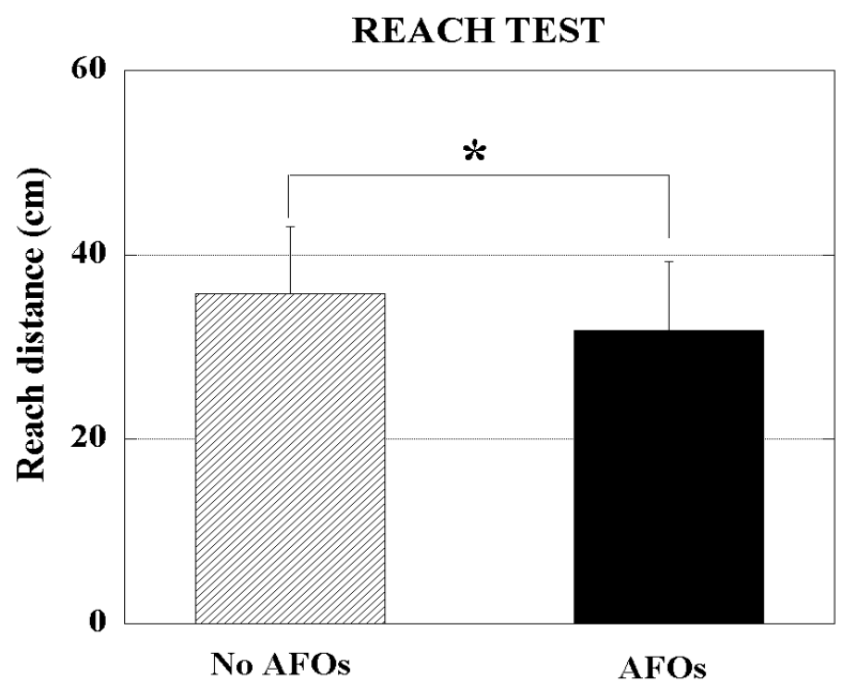

Figure 8. Mean reach distance with and without AFOs. Mean and SD are shown. *Significance $(\mathrm{p}<0.05)$.

In Forward Reach test (Figure 3), the mean reach distance without AFOs was $35.73 \pm 7.37 \mathrm{~cm}$ and when the subjects were provided with AFOs it decreased to $31.81 \pm 7.44 \mathrm{~cm}$. This difference was statistically significant $\left(\mathrm{F}_{(1,9)}=16.04, \mathrm{p}=0.003\right)$. 


\section{CHAPTER V \\ DISCUSSION}

AFOs are commonly used to treat a variety of pathologies affecting joint stability and neuromuscular insufficiency. However, because of their inherent effects on the ankle joint, AFOs may have positive or negative impacts on balance (Seale 2010). Thus, in patients wearing AFOs balance could be affected by two major factors: 1) a disease-related impairment and 2) the AFOs themselves as the AFOs constraint the movements in the ankle joints. Consequently, when individuals using AFOs undergo balance assessment, the outcome of the tests frequently reflects the effect of both, the impairment and AFOs. To evaluate the effect of AFOs per se (and to minimize the effect of the presence of any kind of co-morbidity) we tested healthy individuals. The subjects' performance during the clinical tests of balance involving the Balance Master ${ }^{\circledR}$ (Liston and Brouwer 1996) and Functional Reach test (Duncan et al. 1990) was evaluated with no AFOs and when AFOs were provided. Findings from the present investigation indicate that the performance was affected when administering the clinical tests of balance while using AFOs. Thus, the overall outcomes of the three tests of balance (the modified Clinical Tests of Sensory Interaction on Balance (MCTSIB) and the Limits of Stability test, and the Functional Reach test) demonstrated a decline in the test performance while wearing the AFOs.

\subsection{Role of Ankle Foot Orthoses in modified Clinical Test of Sensory Interaction of Balance}

Increased postural sway in conditions where the subject is instructed to stand quietly (with or without vision and on a firm or compliant surface) is assumed to represent poor balance or decreased stability (Panzer et al. 1995). The mean COG sway velocity was found to be slightly decreased with the eyes open and closed while the subjects were standing on a firm surface with 
AFOs as compared to the no AFOs condition. However, the mean COG sway velocity in both eyes open and eyes closed conditions while standing on a foam surface was significantly higher when the subjects were provided with AFOs. A plausible explanation for the observed AFOrelated differences in the COG sway relates to the fact that the movements in the ankle joints were restricted by the AFOs, and the body sway in such conditions is mostly controlled by activating muscles around the hip joints. Such a control of posture (that resembles a "hip strategy" described by Horak and Nashner was sufficient enough while standing on a firm surface (Horak and Nashner 1986). As a result, almost similar magnitudes of the COG sway were observed in conditions with and without AFOs while standing on a firm surface. Quite the opposite however, the control of posture while standing on a compliant surface required active movements of the ankle joints. When active ankle joint movements were constrained by AFOs (resulting also in restricted sensory input from joint and muscle receptors), the COG sway was significantly larger as compared to the conditions with no AFOs. This outcome correlates with the literature data suggesting that the surface on which the individual is balancing and the availability of sensory cues are important contributors to the selection of strategy for balance maintenance (Nashner et al. 1982). Moreover, the observed AFOs-related increase in the COG velocity is in agreement with the literature, reporting that the largest velocity of postural sway was recorded in patients with functional ankle instability provided with semi-rigid orthoses as compared to a soft or no orthoses at all (Hadadi et al. 2011).

\subsection{Role of Ankle Foot Orthoses in Limits of Stability test}

The LOS test is commonly used in clinical assessment of balance. The LOS test assesses the ability of an individual to control balance in conditions that simulate common activities of daily living that involve lean of the body in different directions and reaching (Wallmann 2001; 
Newstead et al. 2005). The LOS test is considered a reliable assessment of dynamic balance when administered to healthy young and older adults with no recent history of falls (Clark et al. 1997).

The main effect of the AFOs was seen in the end point excursion and maximum excursion $(\mathrm{p}<0.05)$, the two important parameters in the LOS test. It is known that AFOs affect the range of motion and flexibility in the ankle joints (Ramstrand and Ramstrand 2010) and as such this could affect the subjects' ability to move the body in the direction of the target. With no AFOs the subjects were able to voluntarily move their COG to positions within the LOS. However, when they were required to perform the same test while provided with the AFOs (that limited the motion in the ankle joints) the subjects' ability to shift the COG within the LOS was significantly diminished.

At the same time, no differences were found in the mean reaction time and movement velocity between the conditions with and without AFOs. This outcome is not surprising because these two components of the LOS test reflect how fast an individual displaces his/her COG. Indeed, reaction time delays are commonly associated with difficulties in cognitive processing and/or motor diseases and reduced movement velocities are indicative of high-level central nervous system deficits such as Parkinson's disease and age-related disorders (NeuroCom 2010). However, since the subjects were healthy individuals, their abilities to displace the COG were not affected by the use of the AFOs. It is also known that the reaction time and movement velocity could be improved with training; however no training was provided to the study participants. As such, one should not expect to see significant changes in the reaction time or velocity of the body movements during one study session. This outcome is in line with other 
studies reporting that even practicing slow movements does not improve movement velocity component of the LOS test (Gyllensten et al. 2010) .

\subsection{Role of Ankle Foot Orthoses in Functional Reach test}

Maximum forward reach distance is a recognized clinical measure of standing balance and it has been shown to decrease with age (Duncan et al. 1990). It was also shown that a diminished reach distance is strongly correlated with high fall risk in individuals aged 70 years or older (Duncan et al. 1992), individuals with peripheral vestibular disorders (Mann et al. 1996), Parkinson's disease (Brusse et al. 2005) and stroke (Kligyte et al. 2003). Maximum forward reach measures obtained in the current study were consistent with those published by other authors (Duncan et al. 1990; Isles et al. 2004). At the same time, there were AFO-related differences in maximum reach between the conditions. In the current study, AFOs were responsible for the reduction of the reach distance in forward direction: this conclusion is supported by the results of a statistical analysis comparing the maximal reach distance between the conditions with and without AFOs. One can ask a question of why the forward reach distance decreased when AFOs were provided to the subjects. A possible explanation relates to the fact that the AFOs must have restricted the ankle joint movements in the sagittal plane: this was translated into the inability of the subjects to reach as far as they could without taking a step in a forward direction. Normal reaching movements engaging more than one joint are characterized by smooth, approximately bellshaped velocity profiles and straight trajectories (Kuhtz-Buschbeck et al. 1998). It is quite possible that restricting the ankle joint movements induces a multi-joint disco- ordination that might lead to abnormal movement trajectories (Shumway-Cook and Woollacott 2001). Another explanation relates to the possibility of performing reaching movements with different velocities. It was shown previously that healthy women reached further when reaching slowly than when 
reaching rapidly (Kozak et al. 2003). If our subjects truly decreased their velocity of reaching while using AFOs, it would have resulted in reaching further. This however, was not the case since all of the subjects demonstrated lesser reach distances while using AFOs. As such, we believe that the potential differences in the velocity of reaching movements could not be a reason for the decreased reaching distance in the conditions with the AFOs. However, since we did not record the velocity of the reaching movements, a probable role of the velocity of reaching has to be studied further in the future. Finally, it is possible that the use of AFOs was associated with the inability of the subjects to use an ankle strategy during reaching. Previous literature suggests that young subjects could use an ankle strategy while performing a Functional Reach test (Liao and Lin 2008) while it is more common that older adults adopt a hip strategy during performance of the Reach test (Jonsson et al. 2003) (Clark et al. 2005). As such, changes in the maximal reach distance observed in the current study could be due to restriction of movements in the ankle joints related to the AFOs and an inability to use the ankle strategy. 


\section{CHAPTER VI \\ LIMITATIONS AND CLINICAL IMPLICATIONS}

\subsection{Limitations}

One study limitation relates to the small number of subjects. Another limitation relates to the fact that only healthy individuals were tested. As such similar studies need to be conducted involving different patient populations. Future studies can also be conducted using different types of AFOs.

\subsection{Clinical implications}

Knowledge of the AFO-related sources of measurement error can provide meaningful information for clinicians who perform tests of balance or evaluate patient progress during the course of a balance intervention program. One important implication emerging from our findings is that AFOs might negatively affect the outcome of the commonly used clinical balance assessments. Specifically, the ability to move, lean, or reach towards ones stability boundaries was affected with the use of AFOs which is critical to the performance of functional tasks such as picking an object from a shelf, initiation of gait, etc. The study underlines a need for reviewing the descriptions of clinical tests of balance with the focus on clarifying the use of AFOs during the tests so the consistency and repeatability of the assessments is maintained. While the results of the study point out to the adverse effect of AFOs in the outcome of the three clinical tests of balance, this conclusion should be confirmed in the studies involving different patient populations. 


\section{CHAPTER VII CONCLUSIONS AND FUTURE DIRECTIONS}

\subsection{Conclusions}

Ankle foot orthoses that are used to improve ambulation in the patients appear to have a negative effect on the outcome of some clinical tests of balance in healthy adults. This information should be taken into consideration while performing balance evaluations in the clinic. Moreover, the outcome of this preliminary research provides a basis for studying the effect of AFOs in the outcomes of clinical tests of balance in patients.

\subsection{Future directions}

In future research work, effect of unilateral AFO can be studied. Recording electromyographic activity of muscles would help to study different strategies used. Effect of different types of ankle foot orthoses can be studied as well. 


\section{CITED LITERATURE}

Abel MF, Juhl GA, Vaughan CL, Damiano DL (1998) Gait assessment of fixed ankle-foot orthoses in children with spastic diplegia. Arch Phys Med Rehabil 79: 126-133

Brodke DS, Skinner SR, Lamoreux LW, Johanson ME, St Helen R, Moran SA, Ashley RK (1989) Effects of ankle-foot orthoses on the gait of children. J Pediatr Orthop 9: 702-708

Brusse KJ, Zimdars S, Zalewski KR, Steffen TM (2005) Testing functional performance in people with Parkinson disease. Phys Ther 85: 134-141

Butler PB, Farmer SE, Stewart C, Jones PW, Forward M (2007) The effect of fixed ankle foot orthoses in children with cerebral palsy. Disabil Rehabil Assist Technol 2: 51-58

Cakar E, Durmus O, Tekin L, Dincer U, Kiralp MZ (2010) The ankle-foot orthosis improves balance and reduces fall risk of chronic spastic hemiparetic patients. Eur J Phys Rehabil Med 46: $363-368$

Chen CK, Hong WH, Chu NK, Lau YC, Lew HL, Tang SF (2008) Effects of an anterior anklefoot orthosis on postural stability in stroke patients with hemiplegia. Am J Phys Med Rehabil 87: $815-820$

Chen CL, Yeung KT, Wang CH, Chu HT, Yeh CY (1999) Anterior ankle-foot orthosis effects on postural stability in hemiplegic patients. Arch Phys Med Rehabil 80: 15871592

Clark S, Iltis PW, Anthony CJ, Toews A (2005) Comparison of older adult performanceduring the functional-reach and limits-of-stability tests. J Aging Phys Act 13: 266-275

Clark S, Rose DJ, Fujimoto K (1997) Generalizability of the limits of stability test in the evaluation of dynamic balance among older adults. Arch Phys Med Rehabil 78: 1078-1084 
Cohen H, Blatchly CA, Gombash LL (1993) A study of the clinical test of sensory interaction and balance. Phys Ther 73: 346-351; discussion 351-344

Dogan A, Mengulluoglu M, Ozgirgin N (2011) Evaluation of the effect of ankle-foot orthosis use on balance and mobility in hemiparetic stroke patients. Disabil Rehabil 33: 1433-1439

Duncan PW, Studenski S, Chandler J, Prescott B (1992) Functional reach: predictive validity in a sample of elderly male veterans. J Gerontol 47: M93-98

Duncan PW, Weiner DK, Chandler J, Studenski S (1990) Functional reach: a new clinical measure of balance. J Gerontol 45: M192-197

Fatone S, Gard SA, Malas BS (2009) Effect of ankle-foot orthosis alignment and foot-plate length on the gait of adults with poststroke hemiplegia. Arch Phys Med Rehabil 90: 810-818

Gao F, Carlton W, Kapp S (2011) Effects of joint alignment and type on mechanical properties of thermoplastic articulated ankle-foot orthosis. Prosthet Orthot Int 35: 181-189

Genthon N, Gissot AS, Froger J, Rougier P, Perennou D (2008) Posturography in patients with stroke: estimating the percentage of body weight on each foot from a single force platform. Stroke 39: 489

Gyllensten AL, Hui-Chan CW, Tsang WW (2010) Stability limits, single-leg jump, and body awareness in older Tai Chi practitioners. Arch Phys Med Rehabil 91: 215-220

Hadadi M, Mazaheri M, Mousavi ME, Maroufi N, Bahramizadeh M, Fardipour S (2011)

Effects of soft and semi-rigid ankle orthoses on postural sway in people with and without functional ankle instability. J Sci Med Sport 14: 370-375 
Hageman PA, Leibowitz JM, Blanke D (1995) Age and gender effects on postural control measures. Arch Phys Med Rehabil 76: 961-965

Hasso D (2012) Personal communication. In, Wheaton

Hayek S, Hemo Y, Chamis S, Bat R, Segev E, Wientroub S, Yzhar Z (2007) The effect of community-prescribed ankle-foot orthoses on gait parameters in children with spastic cerebral palsy. J Child Orthop 1: 325-332

Horak FB, Nashner LM (1986) Central programming of postural movements: adaptation to altered support-surface configurations. J Neurophysiol 55: 1369-1381

Isles RC, Choy NL, Steer M, Nitz JC (2004) Normal values of balance tests in women aged 2080. J Am Geriatr Soc 52: 1367-1372

Jaivin JS, Bishop JO, Braly WG, Tullos HS (1992) Management of acquired adult dropfoot. Foot Ankle 13: 98-104

Jonsson E, Henriksson M, Hirschfeld H (2003) Does the functional reach test reflect stability limits in elderly people? J Rehabil Med 35: 26-30

Kligyte I, Lundy-Ekman L, Medeiros JM (2003) [Relationship between lower extremity muscle strength and dynamic balance in people post-stroke]. Medicina (Kaunas) 39: 122-128

Kozak K, Ashton-Miller JA, Alexander NB (2003) The effect of age and movement speed on maximum forward reach from an elevated surface: a study in healthy women. Clin Biomech (Bristol, Avon) 18: 190-196

Kuhtz-Buschbeck JP, Stolze H, Johnk K, Boczek-Funcke A, Illert M (1998) Development of prehension movements in children: a kinematic study. Exp Brain Res 122: 424-432 
Lee WA, Deming L, Sahgal V (1988) Quantitative and clinical measures of static standing balance in hemiparetic and normal subjects. Phys Ther 68: 970-976

Liao CF, Lin SI (2008) Effects of different movement strategies on forward reach distance. Gait Posture 28: 16-23

Liston RA, Brouwer BJ (1996) Reliability and validity of measures

Mann GC, Whitney SL, Redfern MS, Borello-France DF, Furman JM (1996) Functional reach and single leg stance in patients with peripheral vestibular disorders. J Vestib Res 6: 343-353

Mulroy SJ, Eberly VJ, Gronely JK, Weiss W, Newsam CJ (2010) Effect of AFO design on walking after stroke: impact of ankle plantar flexion contracture. Prosthet Orthot Int 34: 277-292

Nashner LM, Black FO, Wall C, 3rd (1982) Adaptation to altered support and visual conditions during stance: patients with vestibular deficits. J Neurosci 2: 536-544

NeuroCom (2002) NeuroCom International, Inc., Clackamas, OR

NeuroCom (2010) NeuroCom Users Manual for Smart Balance Master. Clackamas, OR Newstead AH, Hinman MR, Tomberlin JA (2005) Reliability of the Berg Balance Scale and balance master limits of stability tests for individuals with brain injury. J Neurol Phys Ther 29: $18-23$

Panzer VP, Bandinelli S, Hallett M (1995) Biomechanical assessment of quiet standing and changes associated with aging. Arch Phys Med Rehabil 76: 151-157

Pohl M, Mehrholz J (2006) immediate effects of an individually designed functional ankle-foot orthosis on stance and gait in hemiparetic patients. Clin Rehabil 20: 324-330

Radtka SA, Skinner SR, Johanson ME (2005) A comparison of gait with solid and hinged ankle- 
foot orthoses in children with spastic diplegic cerebral palsy. Gait Posture 21: 303-310

Ramstrand N, Ramstrand S (2010) The Effect of Ankle-Foot Orthoses on Balance- A Systematic Review. Official Findings of the State -of-the -Science Conference. Journal of Prosthetics and Orthotics 10: P4-P23

Rha DW, Kim DJ, Park ES (2010) Effect of hinged ankle-foot orthoses on standing balance control in children with bilateral spastic cerebral palsy. Yonsei Med J 51: 746-752

Richie DH, Jr. (2001) Functional instability of the ankle and the role of neuromuscular control: a comprehensive review. J Foot Ankle Surg 40: 240-251

Rubin G, Cohen E (1988) Prostheses and orthoses for the foot and ankle. Clin Podiatr Med Surg 5: 695-719

Seale J (2010) Valid and reliable instruments for the clinical assessment of the effect of AnkleFoot Orthoses on balance. Official Findings of the State -of-the -Science Conference. Journal of Prosthetics and Orthotics 10: P38-45

Sheffler LR, Hennessey MT, Knutson JS, Naples GG, Chae J (2008) Functional effect of an ankle foot orthosis on gait in multiple sclerosis: a pilot study. Am J Phys Med Rehabil 87: 26-32

Shumway-Cook A, Woollacott MH (2001) Motor control : theory and practical applications Lippincott Williams \& Wilkins, Philadelphia

Silver-Thorn B, Herrmann A, Current T, McGuire J (2011) Effect of ankle orientation on heel loading and knee stability for post-stroke individuals wearing ankle-foot orthoses. Prosthet Orthot Int 35: 150-162

Tyson SF, Connell LA (2009) How to measure balance in clinical practice. A systematic review of the psychometrics and clinical utility of measures of balance activity for neurological 
conditions. Clin Rehabil 23: 824-840

Tyson SF, Kent RM (2009) Orthotic devices after stroke and other non-progressive brain lesions. Cochrane Database Syst Rev: CD003694

Wallmann HW (2001) Comparison of elderly nonfallers and fallers on performance measures of functional reach, sensory organization, and limits of stability. J Gerontol A Biol Sci Med Sci 56: M580-583

Yelnik A, Bonan I (2008) Clinical tools for assessing balance disorders. Neurophysiol Clin 38: 439-445 


\section{VITA}

\section{Name}

Nilovana Panwalkar

\section{Education}

- Masters Student (Rehabilitation Sciences)

University of Illinois at Chicago (UIC) - Department of Physical therapy, 2010 to 2012 (expected)

\section{- B. P. Th (Bachelors of Physical Therapy)}

Maharashtra University of Health - KCPT Department of Physical therapy, 2005 to 2010

\section{Research experience and projects}

- Graduate research assistant, Knecht Movement Science laboratory, Department of Physical therapy, UIC, 2010 to present

- "Role of Ankle Foot Orthoses in the outcome of Clinical tests of balance" in collaboration with Dr. A.S.Aruin, 2011 to 2012

- Assisted in various projects conducted in the Knecht Movement Science laboratory, 2010 to 2012

\section{Teaching and administrative experience}

- Teaching Assistant Prep, Department of Biological Sciences, UIC, Spring 2012

Prepared solutions and agar plates used in microbiology laboratory

- Teaching Assistant, Department of Biological Sciences, UIC, Spring 2011

Taught microbiology lab techniques to undergraduate students 
- Graduate Assistant in the Department of Physical Therapy, UIC, Fall 2010. Managed department financial paperwork

\section{Clinical experience}

- Worked as a physical therapy intern in Seth G.S. Medical College and PT school, Mumbai, 2009 to 2010

- Voluntary work in Paraplegic Foundation, Mumbai, October 2009 to November 2009

\section{Participation}

- Chicago Rock n Roll Half Marathon, summer 2011. Ran for organization AID - Association for India's Development

- State Level Conference KNOPSE conducted by KCPT, MUHS, India Worked in the managing committee

\section{Honors and Awards}

- Van Doren Scholarship, UIC, Fall 2011. Amount: \$ 250

- $2^{\text {nd }}$ in B.P. Th. (Bachelor of Physical Therapy), KCPT, MUHS, India

- $3^{\text {rd }}$ in B.P. Th. (Bachelor of Physical Therapy), KCPT, MUHS, India

\section{Publications}

- Panwalkar N, Aruin A.S. Role of ankle foot orthoses in the outcome of clinical tests of balance. Disability and Rehabilitation: Assistive Technology, October 19, 2012. (doi:10.3109/17483107.2012.721158) 